\title{
Peregrinos de Aztlán: narrando los orígenes, reconociendo la nación
}

\author{
Claudia Marcela Páez Lotero \\ University of Massachusetts, Amherst
}

Resumen: El propósito principal de este trabajo es analizar cómo la novela Peregrinos de Aztlán de Miguel Méndez se configura como relato fundacional para darle una identidad a una nación, en este caso la nación de la comunidad chicana que necesita reconocerse a sí misma como tal para así poder emprender la lucha en la consecución de sus derechos civiles. Para ello el texto se acerca a las narraciones fundacionales latinoamericanas desde dos direcciones: cuestionándolas y proponiendo un nuevo tipo que responda a las particularidades de la nación emergente retratada en la novela.

Palabras clave: Miguel Méndez, literatura chicana, Nación, novela fundacional, retórica de la amistad.

\section{Peregrinos de Aztlán: narrating the origins, recognizing the nation}

Abstract: The main goal of this paper is to analyze how the novel Peregrinos de Aztlán, by Miguel Méndez, takes the form of a foundational fiction in order to create an identity for a nation: the one of the Chicano community. This community needs to recognize itself as such and thereby to start its fight for its civil rights. To do so, the text approaches the Latin American foundational fictions from two directions: by questioning them and by proposing a new type of fiction that could meet the distinctive features of the emerging nation described in the novel.

Keywords: Miguel Méndez, Chicano literature, Nation, foundational fiction, rhetoric of friendship. 


\section{INTRODUCCIÓN}

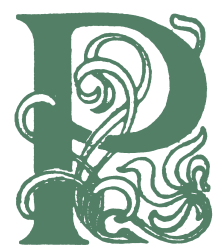

eregrinos de Aztlán (1974), novela del escritor Miguel Méndez (1930-2013), narra la vida de una serie de personajes marginalizados y anónimos que se han movilizado a la frontera entre México y los Estados Unidos buscando una mejor vida. A través de los retratos de esas vidas el autor denuncia el abandono y la miseria a la que han estado sometidos miles de humildes mexicanos y estadounidences de origen mexicano por parte del Estado. Pero además de esto, en la denuncia y en la presentación de esas historias de vida se señalan los orígenes de una comunidad que quiere ser reconocida como tal, ésta es la nación chicana.

Miguel Méndez en Peregrinos de Aztlán busca plasmar la historia de un pueblo para darle legitimidad y conciencia, aproximándese en este sentido a las narraciones que Doris Sommer denomina como ficciones fundacionales, es decir, aquellas novelas nacionales producidas durante el siglo XIX en Latinoamérica, cuyo fin principal era el de narrar la historia de las naciones emergentes proyectando una imagen de éstas y los valores que correspondían a esos proyectos. Sin embargo, la novela de Médez se aleja de aquellas ficciones fundacionales en los modos cómo se aproxima a la realidad histórica bajo la que se funda la comunidad descrita. Si en las novelas nacionales se intenta representar la historia de la nación y, de manera alegórica, proponer unos valores para las jóvenes naciones a través de las relaciones pasionales entre sus héroes y heroínas, en Peregrinos de Aztlán se representa la historia de la nación pero por medio de relaciones de amistad entre sujetos que han sido marginalizados y olvidados de las historias oficiales. El presente ensayo tiene como objetivo analizar cómo Peregrinos de Aztlán se acerca a las narraciones fundacionales latinoamericanas para proponer un nuevo tipo de relato fundacional que responda a la realidad particular de la comunidad chicana.

\section{EL MOVIMIETO CHICANO}

David R. Maciel, Christine Iriart y Amado M. Padilla explican que el pueblo chicano, es decir, la población estadounidense de ascendencia mexicana, 
se caracteriza por ser un grupo minoritario de Estados Unidos incorportado a éste por un proceso de conquista a diferencia de otros grupos inmigrates dentro de dicho país. Ese proceso de conquista tuvo como uno de sus momentos más significativos la Guerra México-Estadounidense (1946-1948). Guerra realizada con fines expansionistas que culminó con el Tratado Guadalupe Hidalgo, con el cual el gobierno mexicano cedió casi la mitad de su territorio. Como consecuencia de esto, miles de mexicanos se encontraron siendo parte de otro Estado, en palabras de los críticos, el pueblo chicano pasó "de ser dueño de su tierra y su destino a ser una minoría explotada" (1980: 104). Por más de un siglo, señalan Maciel, Iriart y Padilla, la comunidad chicana fue victima de discriminación y explotación, y ante esta situación durante las décadas de los ciencuenta y sesenta se conformó el Movimiento Chicano asumiendo la lucha por mejorar las conciones de vida de la comunidad chicana (Maciel, Iriart y Padilla, 1980: 105).

El surgimiento del Movimiento Chicano representó un período de empodaramiento étnico para aquellos habitantes de Estados Unidos de origen mexicano. Luis Leal explica que durante la década de los sesenta, el Movimiento Chicano se apropió de una serie de símbolos como Aztlán, el águila negra, la virgen de Guadalupe, el concepto de la huelga y la expresión « Viva la Raza!», para emplearlos como modos de lucha y afirmación de su identidad cultural (1989: 5); una identidad que, según Maciel, Iriart y Padilla, el pueblo chicano había perdido al incorporarse a la sociedad estadounidense (1980: 105). Estos símbolos, asevera Leal, son de origen reciente a pesar de tener sus orígenes en la historia de México; y de todos ellos fue particularmente Azltán el que mayor cohesión le ofreció al movimiento por su carga mítica (1989: 6-7).

Dentro de la mitología azteca, Aztlán, ubicada en algún lugar al norte de Tenochtitlan, es la ciudad de la que salieron los mexicas guiados por Huitzilopochli, dios de la guerra, en busca del lugar donde fundarían México-Technotitlan (Pina, 1989: 17-28). El Movimiento Chicano retoma este mito para hacer de Aztlán un símbolo que le sirva como fuente de inspiración en su lucha por la autodeterminación cultural. Para ello, asumen a Aztlán como símbolo de doble sentido. Por un lado, lo van a entender como una región geográfica concreta ubicada al sudoeste de Estados Unidos, y compuesta por los territorios que México le cedió a ese país en 1848 con el Tratado de Gua- 
dalupe Hidalgo. Y, por otro lado, va simbolizar la unión espiritual de los chicanos diseminados a lo largo de los Estados Unidos (Leal, 1989: 8). Señala Leal que la primera vez que se menciona a Aztlán dentro de los distintos textos del movimiento fue en «El plan espiritual de Aztlán», manifiesto proclamado en marzo de 1969 durante la primera Conferencia sobre la Liberación de la Juventud. Desde ese momento, afirma Leal, «Aztlán has become the symbol most used by Chicano authors who write about the history, the culture, or the destiny of their people; and the same thing occurs with those who write poetic novels or short stories» (1989: 11). De modo que la imagen de este mito se utilizó para generar tanto una historia ancestral como un discurso cultural propio de esta comunidad.

Como se mencionó anteriormente, las causas de la apropiación de Aztlán provienen de la situación en la que se encontraba la población de origen mexicano en los Estados Unidos durante los años sesenta. Al estar ésta ubicada en los márgenes de una historia y una sociedad, Aztlán le sirve al Movimiento Chicano y a la comunidad que congrega como símbolo y punto de referencia para poder desarrollar todo un pensamiento de nacionalismo cultural; en opinión de Michael Pina, este símbolo le permitiría al pueblo chicano identificarse como: «a spiritual nation rooted in a sacret landscape charged with the power of an indigenous spirituality and justified by the validity of their national liberation struggle» (1989: 36). No obstante, recrear una patria en su sentido espiritual y geográfico no solamente tiene por objetivo la recuperación política de un territorio sino, en principio, también la construcción de una comunidad. Pina afirma que el mito de Aztlán proporciona cohesión y dirección a un conjunto de individuos dispersos. Cohesión porque les permite identificarse con otros a través de una visión común del mundo y de una serie de condiciones sociales compartidas. Dirección porque en ese reconocimiento del otro como congénere asumen como propia la causa: el deseo de construir una nación, en este caso, la nación mestiza que enfatiza sus orígenes indígenas (1989: 38).

Lo anterior explica que la imagen de Aztlán fuera tomada en su manifiesto, «El Plan Espiritual de Aztlán». A través de éste, el Movimiento Chicano abogaba por la unificación de su nación. Para ello hace uso de la idea de nacionalismo cultural, entendido como denominador común de los miembros del movimiento que permite superar las diferencias entre los mismos. En el ma- 
nifiesto se define el ser chicano como el pertenecer a un grupo de personas que son conscientes tanto de su herencia histórica y como de la opresión que han vivido por parte de los Estados Unidos, al que califican como invasor de Aztlán, declarando:

We are free and sovereign to determine those tasks which are justly called for by our houses, our land, the sweat of our brows, and by our hearts. Aztlán belongs to those who plant the seeds, water the fields, and gather the crops and not to the foreign European. We don't recognize capricious frontiers on the bronze continents (El Plan, 1989: 1).

Esto quiere decir que entienden la lucha por su territorio y sus derechos como su responsabilidad y su destino ya que se asumen como habitantes soberanos del mismo.

\section{IMAGINANDO LA COMUNIDAD}

Miguel Méndez, como parte del Movimiento Chicano, responde al ideario de éste a través de su escritura. Al igual que los escritores latinoamericanos del siglo XIX, este autor va a recurrir a la ficción para contar la historia de su nación, pero no la historia oficial porque ésta, como bien señala el narrador de Peregrinos de Aztlán, "coqueta liviana, los desdeña, como toda puta que no otorga favores si no pulsa el oro de la paga» (Méndez, 1991: 156). Para tal efecto, recurre a la historia de los marginados, que es la historia de la nación chicana. Y como ficción fundacional, Peregrinos de Aztlán va a narrar los orígenes de esa nación para auto-afirmarla, para hacer que distintos individuos se identifiquen con ella a pesar de su dispersión en torno al espacio de la frontera. En otras palabras, lo que se busca es reconocer a una comunidad imaginada como una nación concreta.

Benedict Anderson, en Imagined communities, define el concepto de nación como «an imagined political community - and imagined as both inherently limited and sovereign» (1991: 6). Imaginada porque, aunque los miembros de esa nación nunca se conocerán, tendrán la imagen de esos otros miembros como un conjunto al que todos pertenecen; limitada porque se establecerán unas fronteras geofráficas concretas; soberana porque esto le garantiza su libertad; y como comunidad porque puede percibirse como una fraternidad. 
Es importante mencionar que ese imaginarse, limitarse y percibirse como comunidad soberana es una construcción que cada grupo se plantea sobre sí mismo. A demas de esto, dentro de esa nación es posible construir una identidad nacional, entendida por Gellner como autoconciencia de pertenecer a una cultura (Ctd. en García, 1994: 167). Para Juan García, la identidad nacional se establece por un proceso de reflexión, es decir, de observarse a sí mismo en el espejo para apreciarse en el reflejo que es el otro. Esto con el fin de que la comunidad al reflejarse en el otro pueda construir una imagen de sí misma a partir de la diferencia, con lo cual es posible establecer un principio de homogeneidad cultural con el que la comunidad puede observarse a sí misma con unos rasgos comunes a todos sus miembros (1994: 165-183).

Lo anterior puede apreciarse en Peregrinos del Aztlán al verse reflejado el nacimiento de una nación que intenta legitimarse pero que primero debe imaginarse. Los miembros de dicha nación en la novela no se conocen pero intuyen la existencia de sus congéneres. Esto se puede observar en las visiones que nos ofrece Loreto Maldonado de los distintos personajes que participan en la narración; visión cuya presencia constante, inica Lomeí, funciona como un hilo conductor que permite se irradien las demás voces narrativas y que intervengan fragmentando el texto sin destruir su unidad. Así, Loreto ofrece al relato «unidad situacional, espacial y trasfondo histórico a lo narrado» (Lomelí, 1991: 12). Y a su vez, al hacer esto, reconoce la existencia de esos sujetos:

Las voces que abortaban las calles, los callejones sórdidos y los tugurios, tantas voces llagadas con dolor humano, huían del planeta amargo a guarecerse en las cavernas de los vastos mundos de la mente de los seres sensibles. Así le llegaban los lamentos al yaqui Loreto, contando historias vulgares que a nadie conmueven, pese a lo trágico, porque se repiten a cada día con un martillo feroz que nunca cesa (Méndez, 1991: 58).

Sumado a esto, se ponen en evidencia los orígenes e historias en común de tales personajes: mexicanos migrantes a causa de la pobreza y el hambre generada por la corrupción del Estado y su discriminación hacia el campesino y el indígena.

En cuanto a los límites de esa comunidad, la primera referencia la encontramos en el título mismo de la novela: Peregrinos de Aztlán, que nos indica el 
origen y pertenencia de esos migrantes. A parte de este paratexto, la palabra Aztlán aparece apenas dos veces dentro del texto. La primera, se refiere a la ciudad de Los Ángeles, y se presenta cuando uno de los narradores se encuentra con el Chuco, un trabajador que emigra a los Estados Unidos: «Las piedras rodando se encuentran. Pasados diez años, por mera casualidad, topé con el buen Chuco en el centro de Los Ángeles, Aztlán» (1991: 44). En este caso, la ciudad se presenta como un territorio propiamente aztlanense y ya no como parte de los Estados Unidos. Y, en cuanto a la segunda mención, ésta se presenta en la segunda parte del texto cuando se habla acerca de los antepasados de la acaudalada familia Foxye, oriunda de los Estados Unidos, en el momento en el que su único heredero regresa a casa convertido en un hippy. Refiriéndose precisamente a este último, opina el narrador: «Qué suerte que no pudieran verlo sus gloriosos antepasados, aquellas damas todas delicadeza y pudor, los caballeros aquellos tan pulcros y honorables, predestinados por el Señor a fundar un paraíso en tierras de Aztlán» (1991: 116). Dichos antepasados, se explica en la novela, son los peregrinos británicos que arribaron a América en el Mayflower. Se puede apreciar en la anterior cita cómo se asevera la existencia física de Aztlán desde antes de la llegada de los padres peregrinos durante el siglo XVII. El narrador presenta a Aztlán como una tierra ya nombrada y habitada, y no recién descubierta y libre para ser colonizada. Estas dos menciones a Aztlán se pueden interpretar como formas de reconocimiento y expresión de soberanía que los propios personajes hacen sobre el lugar físico que habitan, un lugar del que ellos han formado parte desde antes de la conquista y colonización europea, y al que siguen perteneciendo en el presente de la narración.

Añadido a esto, los márgenes de esa comunidad quedan señalados en los espacios donde tienen lugar los hechos narrados: la frontera entre México y Estados Unidos, específicamente la ciudad de Tijuana, y el desierto de Sonora. Lugares en donde los chicanos ubican geográficamente a Aztlán, y que de hecho hacia el final de la novela son enfatizados cuando uno de los personajes sale a recorrer su territorio: «Con sus poderosas alas Pánfilio Pérez se echó a volar por todos los confines donde vive la raza chicana: las vastedades de Arizona, Nuevo México, Texas; por todas partes clavó la vista viendo $\mathrm{y}$ viendo a su gente» $(1991,179)$.

De modo que en la novela los personajes se imaginan, son conscientes de la existencia de los otros y del espacio común en el que habitan, pero solo pa- 
san a conformar una comunidad cuando se piensan como una fraternidad. Precisamente, esto último es enfatizado por el Movimiento Chicano en «El plan espiritual de Aztlán»: «Brotherhood unites us, and love for our brothers makes us a people whose time has come and who struggles against the foreigner "gabacho" who exploits our riches and destroys our culture» (1989: 1). Esto quiere decir que este movimiento no solo reconoce una serie de condiciones y dificultades sociales compartidas, sino también unos lazos de familiaridad. La comunidad se materializa a partir del reconocimiento del otro como igual y al establecer un lazo de pertenencia con él basado en el amor. Esto se deja ver cuando Loreto expresa su compasión por personajes como Chayito (el niño lavacoches), la Malquerida (víctima de la trata de personas y que por ello termina en la prostitución) o, como se puede apreciar en la siguiente cita, por el Cometa (el artista que alguna vez fue famoso pero que cae en la indigencia):

En la cara prieta del indio [Loreto] floreció una sonrisa espontánea que a modo de adiós ofrendó a la viejecita sentimental. Se alejaba sintiendo en el corazón una profunda conmiseración por aquel ser misterioso [el Cometa] que se allegaba a la caridad pública para poder subsistir, igual que hacen los perros que no tienen dueño (1991: 120).

Loreto expresa un sentido de piedad y solidaridad hacia todos esos sujetos que han sido marginados y, vale la pena resaltar, quien expresa estos sentimientos es un individuo en las mismas condiciones, un marginado como ellos.

\section{UNA RETÓRICA DE LA AMISTAD}

El lazo de pertenencia entre los personajes, basado en un amor fraternal o de amistad, es precisamente lo que aleja Peregrinos de Aztlán de las ficciones fundacionales latinoamericanas del siglo XIX. Doris Sommer explica que el objetivo de las novelas nacionales decimonónicas era configurarse «como fuente de la historial local y orgullo literario» (2004: 20) de las naciones emergentes. A través de ellas se quería contar la historia de la formación de la nación y reflejar la unidad y valores de la misma. Estas novelas nacionales, indica Sommer, tienen como comun denominador narrar historias de pasión romática, tipo de pasión que «proporcionó una retórica a los proyectos he- 
gemónicos en el sentido expuesto por Gramsci de conquistar al adversario por medio del interés mutuo, del "amor", más que por la coerción" (2004: 23). A través de la retórica del amor erótico se presentaba la lucha de héroes y heroinas que buscan superar una serie de dificultades para estar juntos, dificultades siempre externas a la relación amorosa. Por medio de la unión de estos personajes se ejemplificaba, por un lado, la consolidación de la nación al superar los antagonismo en su interior y, por otro lado, se proyectaba el anhelo de crecimiento y desarrollo nacional, objetivo de la relación erótica (Sommer, 2004: 41). De manera que en las novelas nacionales latinoamericanas, el destino nacional estaba estrechamento vinculado con la pasión personal vivida por los amantes, es decir, el destino de los amantes era alegoria del destino de la nación (Sommer, 2004: 43).

A pesar de que en Peregrinos de Aztlán se continúa una retórica del amor, esta ya no va a estar basada en la relación eros y polis sino más bien en la relación philia y polis. Miguel Martí explica que para Aristóteles la philia o amistad era una virtud social o política que permitía regular las relaciones entre los sujetos de la polis, de modo que el tipo de amistad era proporcional al tipo de bien que los sujetos querían para sus amigos (Martí, 2017: 40-41). Aristóteles observa cuatro tipos de amistad: amistad por interés o utilidad, amistad por placer, amistad plena, y amistad cívica. De todas estás la más central para Aristóteles era la philia teleia o amistad plena ya que ésta estaba fundada en el carácter de excelencia tanto del individuo como del amigo, y sobre este tipo de amistad se podía establecer la philia politike o amistad civil (Martí, 2017: 41). La amistad civil se expresa a través de la concordia, relación que, según Augustín Palomar, en Aristóteles se entiende como aquella «que se da en el marco de la pólis cuando esta es gobernada desde el acuerdo muto de los ciudadanos» (2014: 57).

Para que se pueda reconocer una relación como philia o amistad propiamente dicha para Aristóteles, explica Martí, se deben dar las siguientes condiciones: reciprocidad entre los amigos, reconocimiento de la amistad profesada entre ellos, el querer el bien del otro, la posesión del carácter excelente por parte de quienes profesan una amistad, la concordia o convivencia en comunidad, y el amor propio que el permite querer el bien del prójimo (Martí, 2017: 40-41). En cierta medida estas condiciones se dan entre los personajes de Peregrinos de Aztlán. Las relaciones que establecen los personajes de la no- 
vela de Miguel Méndez están fundadas en el reconocimiento de la dignidad o excelencia del otro y en el querer el bien para éste.

Peregrinos de Aztlán no busca representar las relaciones de amor pasional entre héroes y heroínas que alegorizan el proceso de conformación, unidad y desarrollo de la nación; por el contrario, la novela pretende reflejar relaciones de amistad que evidencian las dinámicas y la realidad de la comunidad chicana. Se trata de presentarle al lector personajes del común que representan a todos los sujetos de la comunidad, quienes a su vez se reconocen como hermanos dignos de ser respetados, como es el deseo de los wetbacks:

Ya nunca más lastimaría mi alma con las espinas del desprecio y de la indiferencia, sería en el futuro un verdadero ciudadano que pide y recibe justicia. Me ganó la ilusión y vi en la cósmica soledad del desierto Sonora-Yuma la república que habitaríamos los espaldas mojadas, los indios sumidos en la desgracia y los chicanos esclavizados. Sería la nuestra, la ‘República de Mexicanos Escarnecidos' (1991: 96).

Las aspiración de esta voz es la de todos, cada uno actúa como sinécdoque: el individuo que representa a toda la comunidad, la cual manifiesta su deseo de ser reconocida, respetada y tratada con dignidad por ese otro que la ha oprimido y la ha sumido en la pobreza.

No obstante, la novela no deja de representar la diversidad de esa comunidad. Esto lo hace a través de la reproducción de distintos registros del habla. En la narración cada personaje tiene un habla particular, con lo que se manifiesta su origen geográfico, clase social, nivel de educación, etc. Estrategia similar a la utilizada en las novelas fundacionales, en las que se reproducía el habla oral para diferenciar a los personajes de la ciudad de los del campo y así presentar a estos últimos como sujetos exóticos que le ofrecen a la narración cierto color local, como en el caso de Doña Bárbara de Rómulo Gallegos y La vorágine de José Eustasio Rivera. Pero a pesar de esta similitud Peregrinos de Aztlán se aleja de estas novelas. Al reproducir distintos registros del habla no solamente se destaca la diversidad de la comunidad representada sino que también se les coloca en el relato como sus protagonistas sin llegar a exotizarlos. Mientras que en las otras novelas la exotización de los personajes rurales servía para enfatizar la necesidad de educar o civilizar al llano o a la selva por parte de los personajes de la ciudad (es el caso de la relación 
entre Marisela y Santos Luzardo en Doña Bárbara), y para configurar a estos últimos como protagonistas de la narración y padres de la patria, en el caso de la novela de Méndez, todos los personajes son protagonistas y todos son padres de la patria ya que todos la fundan a través de sus historias de opresión y lucha.

\section{ENTRE LA HISTORIA Y LA INTRAHISTORIA}

Regresando al cambio en la retórica erótica por una de la amistad, éste también implica un cambio en el vínculo entre la ficción y la historia. Peregrinos de Aztlán no pretende recrear la historia incompleta de la nación para establecerla oficialmente, sino contar la historia de las orillas que no está incompleta sino silenciada. Esto se realiza al darle voz a personajes marginalizados: lavacoches, vendedores ambulantes, prostitutas, trabajadores del campo, wetbacks, etc.; personajes que no sustentan una posición de poder y que no podrían ser elevados a la categoría de héroes, pero que de todas formas componen la nación. Sin embargo, la novela no sólo se limita a hacer presente esa historia para ponerla a circular dentro del mundo sino que además, es una invitación a seguirla generando.

Al hacer visibles a los marginados escribiendo su historia, Méndez parece estar moviéndose entre las nociones de historia e intrahistoria como las entiende Miguel de Unamuno. Celso Median explica que para el filósofo español, la primera corresponde a una serie de eventos espectaculares y superficiales que conforman la historia oficial; mientras que la segunda se refiere a la cotidianidad de sujetos anónimos que producen los cambios que se reflejan en la historia, es decir que:

La historia es entonces 'el espectáculo', que necesita estrategias 'seductoras'. Por ello se ve obligada a convertir a sus protagonistas en héroes, cuyas hazañas impacten en el escenario donde acuden los espectadores ávidos de intrigas. Frente a ese modelo, Unamuno propone una intrahistoria sin héroes, en la que las jerarquías de los protagonistas desaparecen. El hacer intrahistórico es una tarea de todos. Todos los hombres importan en tanto que contribuyen a impulsar el continuum de la tradición eterna (2009: 128).

Y esto es evidente en la novela de Méndez, todas las voces tienen valor y todos los personajes producen los cambios. La representación de su miseria 
compone la realidad de la frontera, una realidad que se intenta transformar, como se puede apreciar hacia el final de la novela cuando los hijos de los peregrinos buscan el fin de esos dramas al asumir el territorio habitado como suyo y al identificarse como chicanos propiamente, ya no como estadounidenses o mexicanos inmigrantes. Para ellos ya no hay un lugar a donde retornar, como si lo tuvieron sus padres alguna vez:

Usted y yo y muchos más hemos vivido con la idea de volver algún día al terruño, lo demás nos ha importado un bledo, por eso nos hemos dejado pendejear. Pero ellos, mi amigo, son nacidos y criados aquí y no soportan más que los sigan tratando como a borregos, negándoles empleos y educación, montándolos en las guerras nomás porque se les pone (1991: 183).

El juego de voces en Peregrinos de Aztlán bien podría responder a esa noción de intrahistoria. Todas las voces dan testimonio de ese continuum que no necesariamente implica la vivencia constante de una misma situación. Medina explica que para Unamuno «lo cotidiano trabaja en un espacio paradójico. Es rutina, pero también es cambio. En él se urde la trama del mundo, que conserva, cambia y desecha experiencias. En justicia, es allí donde realmente acontece la historia» (2009: 130). Lomelí explica que en Peregrinos de Aztlán la presencia de las voces anónimas es una forma de ofrecerles en el texto un lugar para sublevarse, porque les permite circular en el mundo del lector quien, a su vez, dejaría de observarlas como ingenuas, pues ellas mismas tienen consciencia de su condición y de su drama, como ocurre con Loreto: «Por un momento creyó escuchar el zumbido de los barrancos y el silbar enloquecido de las cañadas. No, el viejo Loreto ya no era cualquier campesino ingenuo. [...]. Aquel supuesto aguacero en ciernes no era otra cosa que mares de gasolina y aceite» (1991: 25). Entonces, el lector tendría la oportunidad de ver a esos sujetos desde una perspectiva compasiva y comprensiva (Lomelí, 1991: 9). Y es ahí donde la intrahistoria puede producir el cambio, al presentar la cotidianidad de un sufrimiento y conmover a ese otro que tiene el poder para actuar en el mundo y generar una conciencia colectiva sobre tales problemáticas. Ese es el llamado que se hace al final de la narración: «El destino es la historia y la historia es el camino tendido ante los pasos que no han sido» (1991: 184). Por lo tanto, se pretende generar historia y trazar un nuevo camino para esa nación. 
No obstante, la historia oficial no queda excluida de la novela, ésta más bien se convierte en el telón de fondo que viene a explicar la condición de la cotidianidad representada. El drama de los peregrinos es producto de unas circunstancias históricas concretas: la persecución hacia el indígena durante el gobierno de Porfirio Díaz (1830-1915); la Revolución mexicana de 1910; y las políticas económicas de los Estados Unidos, en concreto, el Programa Bracero (1942-1964). El peregrinaje que, como bien explica Lomelí, es búsqueda espiritual y de una calidad de vida, se produce por el hambre que los personajes han vivido desde antes de la Revolución mexicana. Pero asimismo, ese telón de fondo está marcado por el presente de la narración. Como se mencionó, la historia para Unamuno es de carácter continuo y por ello no se limita simplemente a los eventos del pasado sino que también atañe al presente. Esto se puede observar en la novela al contextualizar los hechos narrados en un lugar y tiempo determinados. Lomelí indica que la ciudad representada en Peregrinos de Aztlán bien podría ser Tijuana por la mención de las calles y los centros nocturnos. Y, de acuerdo con las referencias temporales de la novela, ésta parece desarrollarse durante los años de la Guerra de Vietnam (1959-1975). De modo que Méndez no solo nos ofrece las causas de la emigración sino también las circunstancias bajo las que se vive ese drama en el presente de la novela. El autor también describe otras cuestiones: las relaciones entre los chicanos y los foráneos, la discriminación racial, y el problema de la degeneración social de las clases acomodadas, ejemplificado por Don Mario Miller de Cocuch y Doña Reginalda Dávalos de Cocuch (pareja de millonarios que poseen prostíbulos en donde trafican con mujeres y que además por medios dudosos llegan a hacer parte del gobierno).

Así pues, la historia que se recoge en Peregrinos de Aztlán no es la historia incompleta de una nación sino la que ha circulado en medios relegados:

Así la historia, de pronto, como en un mal sueño nos dejó varados en la isla del olvido, presos. No sólo eso, han quedado encadenados los genes que guardan la cultura, esencia de nuestra historia, vedando las arterias como ríos traen el ímpetu de la sangre que anima la voz y el alma de nuestro pueblo. Ni dignidad ni letras para los esclavos, dijeron los dominadores, solamente la ignominia, la burla y la muerte (1991: 183-84).

De esta manera, el autor pone en forma escrita la historia de su nación para no perderla y para que pueda circular entre los miembros de la comunidad. 
Y en esa historia resaltan los valores de la nación reflejados en la cotidianidad de esos personajes anónimos y marginalizados, como acontece con el buen Chuco quien representa al trabajador aplicado y poseedor de una fuerza descomunal, que es la misma fuerza que poseen los chicanos.

A ese pueblo chicano en formación dentro de Peregrinos de Aztlán también se le asigna un origen cultural cuyos valores y dignidad deben ser exaltados. Esto puede explicar el final de la novela, el cual parece ser un llamado a la unión y al cambio. Los peregrinos de Aztlán salen de sus tierras en busca de un lugar mejor, en busca de la tierra que los dioses les prometieron. Pero Méndez, siguiendo el ideario del Movimiento Chicano, ya no hace énfasis en esa búsqueda frustrada sino más bien en la construcción de ese Aztlán en el presente de ese pueblo e invita al establecimiento de esa nación y a la lucha legítima por sus derechos. En consecuencia, Aztlán no es solamente ese lugar geográfico anhelado sino que también son los sujetos destinados a habitar ese territorio como consecuencia de la peregrinación o migración que han vivido. Sujetos de orígenes diversos pero unidos por los valores y las historias de movilización que tienen en común.

Y, además de ello, Aztlán es el derecho de la comunidad a controlar su propio destino según sus propios deseos. Ese derecho igualmente tiene que ver con la imagen de la guerra que se presenta en la novela. La guerra de Vietnam también es referida dentro de Peregrinos de Aztlán como un modo de admisión oficial dentro de un Estado. Sin embargo, más que una puerta de ingreso y aceptación, la guerra en la novela se muestra como una trampa: «Ellos, los más débiles, iqué gran privilegio!, tenían la distinción de morir en un promedio más elevado, sacrificándose así por la noble patria y honrando las consignas de los preclaros, sabios, gloriosos halcones. ¡Loor a los valientes halcones!» (1991: 155). Los chicanos en la novela ingresan al ejercito con la esperanza de llegar a ser considerados como parte de un Estado, el de los Estados Unidos, para así poder reconocer no solo un lugar de pertenencia sino también para poder acceder a servicios como la educación, con la que podrían tener mejores opciones laborales y así mejorar su calidad de vida. Sin embargo, en la guerra le sirven a ese Estado que los sigue rechazando pero que se aprovecha de ellos, por lo que terminan siendo usados como carne de cañón. Con su muerte en la guerra se profundizan las dificultades de sus familias como acontece con Panfilio, quien al perder a su hijo enloquece y 
termina consumido en el alcohol, incapaz ya de trabajar en los campos para sustentar a los suyos.

En correspondencia con lo anterior, esta novela problematiza otro asunto relevante en la construcción de esa comunidad: la identidad nacional, la cual dentro de la comunidad imaginada genera una conciencia de pertenencia a una cultura. Esto último, dentro de la novela, se aborda también a través del buen Chuco, quien en su tránsito en la frontera comienza a cuestionarse acerca del grupo social al que pertenece y con el que se identifica: «Allá, ése, pos es uno "greaser", un "Mexican"; viene uno acá, ése, y quesque uno es "pocho"; me empieza a cuadrar que me llamen chicano, bato, me cai a toda madre, carnal, si quiera ya es uno algo, no cualesquier greaser o pocho» (3738). El Chuco se encuentra en conflicto frente a las comunidades de las que podría ser parte porque éstas, a su vez, lo rechazan: pocho del lado mexicano, del espacio de sus orígenes; greaser del lado estadounidense, del lugar al que contribuye como trabajador. José Manuel Valenzuela Arce explica que la imagen del pocho, o mexicano emigrante, es una recreación cultural que desde México se realiza acerca del otro lado de la frontera norte; es una imagen estigmatizada que enmarca a una serie de sujetos que se considera han perdido su identidad nacional, pues en su contacto con los Estados Unidos se contaminan y se doblegan ante los que han mutilado a la nación. Asimismo, del lado de los Estados Unidos el mexicano es estereotipado como sujeto relajado, primitivo, perezoso, violento y sodomita que con su llegada a dicho país pone en riesgo la seguridad de éste en términos culturales, morales y económicos (2003: 39-45). Al identificarse como chicano, el Chuco comienza a diferenciarse de esos otros que lo niegan y a reflejarse en los que como él se han desplazado hacia la frontera en busca de un mejor porvenir y que, como consecuencia de políticas económicas discriminatorias, han sido explotados. Reflexión con la que gana dignidad y un lugar en el mundo.

Todo esto tal vez pueda responder al tipo de sujeto que se describe en «El Plan Espiritual de Aztlán». Esa gente nueva, La Raza de Bronze, no se identifica ni como descendientes de europeos, es decir, no reconoce tener raíces españolas, ni como estadounidenses o gringos; más bien estos dos son vistos como extranjeros e invasores. Pero sí se identifican como mestizos descendientes de los primeros pobladores del suroeste de los Estados Unidos, descendientes que vivieron un proceso de inmigración que más que nada repre- 
senta un regreso a la tierra ancestral. De ahí que la identidad chicana dentro de la novela sea asumida totalmente por la generación de los descendientes de los peregrinos. Estos, a diferencia de personajes como el Chuco, no viven la división entre dos espacios:

Mi hijo me lo aclaró: 'Apá, nosotros aquí vamos a vivir hasta que entreguemos el equipo, y aquí van a vivir nuestros chavalos; como ya nos llenaron los calcos de tachuelas, pos más vale darnos en la madre por lo que es justo, si no, todo el tiempo nos van a tener con la pata en el pescuezo [...]'. Viéndola desde allí, póngase a pensar y verá que tienen sus razones los chamacos (1991: 183).

Los descendientes ya no buscan a Aztlán sino que se asumen como sus naturales. Por ello exigen se les reconozcan sus derechos como habitantes propios de ese territorio en el que identifican un origen, una historia y una cultura. Derechos a los que no deberían acceder por medio de su participación en la guerra sino por su reconocimiento oficial como habitantes genuinos de ese espacio.

Lo anterior permite cuestionar la relación entre el Estado y la nación expuesta en esta novela. Mientras que en las novelas fundacionales decimonónicas la construcción de una nación coincidía con la construcción de un Estado, la nación de Peregrinos de Aztlán no pretende construir uno nuevo. Por el contrario, se reconoce la existencia de los ya establecidos: México y Estados Unidos, pero lo que se busca es la aceptación de la comunidad chicana como tercera nación ubicada en el espacio de aquellos dos Estados. Con ello la nación chicana les exige el respeto por sus derechos como habitantes legítimos.

\section{CONCLUSIÓN: FUNDACIÓN DESDE LAS TRAGEDIAS}

En síntesis, Peregrinos de Aztlán se aproxima a las ficciones fundacionales del siglo XIX en sus objetivos: narrar la historia silenciada para dar coherencia y cohesión a una comunidad que necesita reconocerse y ser reconocida como tal; describiendo la fundación de la nación chicana a partir de una retórica de la amistad y ya no erótica. En ella todos los sujetos tienen el mismo valor como seres humanos y todos participan en la transformación y continuum de la historia. Con ello, se hacen visibles los dramas socioeco- 
nómicos de la comunidad chicana para así denunciarlos y buscar cambios en esa realidad. Entonces, la novela se acerca a la ficción fundacional desde el fracaso, desde las tragedias de los peregrinos que ocupan la frontera. A partir de ese espacio y esa historia se comienza a gestar la identidad de una comunidad que necesita reconocerse a sí misma para poder emprender la lucha por sus derechos. Así, Méndez funda una comunidad en su ficción para darle libertad y legitimidad, siguiendo de este modo los idearios del Movimiento Chicano.

\section{REFERENCIAS BIBLIOGRÁFICAS}

Anderson, Benedict (1991), Imagined communities, New York: Verso.

- (1989), «El plan espiritual de Aztlán», en Rudolfo Anaya y Francisco Lomeli (eds.), Aztlán. Essays on the Chicano Homeland, Albuquerque, El Norte Publications, págs. 1-5.

GARCíA, Juan (1994), «Nación, identidad y paradoja: una perspectiva relacional para el estudio del nacionalismo», en Reis, 67, págs.165-183.

Leal, Luis (1989), «In Search of Aztlán», en Rudolfo Anaya y Francisco Lomeli (eds.), Aztlán. Essays on the Chicano Homeland, Albuquerque, El Norte Publications, págs. 6-13.

Lomelí, Francisco (1991), «Introducción: Peregrinos de Aztlán de Miguel Méndez: Textimonio de desesperanza(dos)» a Miguel Méndez, Peregrinos de Aztlán, Tempe, Bilingual Press/ Editorial Bilingüe, págs. 1-17.

Maciel, David R., Christine Iriart De Padilla y Amado R. Padilla (1980), «Los Chicanos: ensayo de introducción», en Tino Villanueva (Comp.), Chicanos: antología histórica y literaria, México, Fondo de Cultura Económica, págs. 104-119.

- (2018), «El florecimiento cultural chicano», en Nexos: Sociedad, Ciencia, Literatura, 490, pág. 82-86.

Martínez, Miguel (2017), «Amistad y reconocimiento. Sobre la philia aristotélica. Lo que Aristóteles vio y Hegel pasó por alto», en Revista internacional de filosofía, 2, págs. 37-49. 
Medina, Celso (2009), «Intrahistoria, cotidianidad y localidad», en Atenea, 500, págs. 123-139.

MéNDez, Miguel (1991), Peregrinos de Aztlán, Tempe, Bilingual Press/ Editorial Bilingüe.

- (1997), «Mi peregrinar en Peregrinos de Aztlán», en Revista Española de Estudios Norteamericanos (Reden), 13, págs. 9-16.

Martín-Rodríguez, Manuel M (1995), «En la frontera del lenguaje: escritores y lectores en Peregrinos de Aztlán», en Gary D. Kelle (ed.), Miguel Méndez in Aztlán: Two Decades of Literary Production, Tempe, Bilingual Press/ Editorial Bilingüe, págs. 57-70.

Palomar, Augustín (2014), «La philía como investigación fenomenológica particular del saber práctico de Aristóteles: significado y fundamentación», en Franciscanum, 162, págs. 51-73.

PinA, Michael (1989), «The Archaic, Historical and Mysthicized Dimensions of Aztlán», en Rudolfo Anaya y Francisco Lomeli (eds.), Aztlán. Essays on the Chicano Homeland, Albuquerque, El Norte Publications, págs. 14-45.

RAmíreZ, Axel (2000), «Espejos y reflejos: los chicanos y su literatura en México», en Tema y Variaciones de literatura, 14, págs. 21-36.

Saldivar, Ramón. (1990). Chicano Narrative. The Dialectics of Difference, Wisconsin: The University of Wisconsin.

Sommer, Doris (2004), Ficciones fundacionales, Bogotá, Fondo de Cultura Económica.

Valenzuela ArCe, José Manuel (2003), «Métaforas y debates teóricos sobre la frontera México-Estados Unidos», Por las fronteras del norte, México, Fondo de Cultura económica, págs. 33-67. 